\title{
Effects of Parental Smoking on Occurrence of Childhood Acute Leukemia
}

\author{
Fumio Bessho ${ }^{1,}$, , Masako Tanimura ${ }^{2}$ \\ ${ }^{1}$ Department of Education of General Medicine, Faculty of Health Sciences, Nihon Institute of Medical Science, Saitama, Japan \\ ${ }^{2}$ Department of Pediatrics, Kyorin University School of Medicine, Tokyo, Japan
}

Email address:

bessho@ks.kyorin-u.ac.jp (F. Bessho)

${ }^{*}$ Corresponding author

To cite this article:

Fumio Bessho, Masako Tanimura. Effects of Parental Smoking on Occurrence of Childhood Acute Leukemia. European Journal of Preventive Medicine. Vol. 8, No. 5, 2020, pp. 61-65. doi: 10.11648/j.ejpm.20200805.11

Received: August 28, 2020; Accepted: September 11, 2020; Published: September 23, 2020

\begin{abstract}
We herein determined the effects of parental smoking on occurrence of childhood acute leukemia using the large volume of data accumulated in the Japan Children's Cancer Registry. Information on the smoking statuses of fathers was available for 4,802 acute leukemia cases diagnosed between 1985 and 2006 and that of mothers was available for 5,536 cases diagnosed between 1978 and 2006. We compared the smoking rates of parents whose children were diagnosed with leukemia with a control group of parents whose children were diagnosed with benign tumors or cancer-related diseases. The smoking rate of fathers was significantly larger than the control. The odds ratios were 1.284 for 1-9 cigarettes/day (c/d) before conception $(\mathrm{p}=0.127), 1.265$ for $10-19 \mathrm{c} / \mathrm{d}(\mathrm{p}=0.029)$, and 1.345 for more than $20 \mathrm{c} / \mathrm{d}(\mathrm{p}=0.000)$. A logistic regression analysis controlling for sex, birth weight, paternal age at birth, and maternal smoking showed that the smoking rate of fathers whose children had acute leukemia was still significantly higher (OR 1.012, $\mathrm{p}=0.004)$. The difference of the smoking rate between mothers whose children had acute leukemia and the control mothers was not significant (OR 1.161, $\mathrm{p}=0.447$ ).
\end{abstract}

Keywords: Childhood Acute Leukemia, Parental Smoking, Sperm, Fetus

\section{Introduction}

Tobacco contains many genotoxic substances and causes various kinds of cancers, even in persons exposed to secondhand smoke [1]. These genotoxic substances exert more profound effects on young children than on adults, and may be transferred to the fetus through the placenta [2] Metabolites of substances originating from tobacco and damaged lymphocytes have been detected in the umbilical cord blood of newborns [3-5]. Many studies were conducted in an attempt to elucidate the effects of these substances on the development of cancers in the children of smoking parents [6-12]. However, many of these studies showed that father's smoking had rather higher risk for childhood cancer development than mother's smoking $[6,8,11,12]$. This is somewhat peculiar because genotoxic substances could directly affect fetus through placenta. One of the reasons might be the relatively small sample size of the past studies. The studies with small sample size have weak statistical power and the results tend to be unstable. For example, one previous study showed that father's smoking was related to childhood ALL for total smokers, but this effect disappeared for heavier smokers [8]. Therefore, we investigated the effects of parental smoking on the occurrence of childhood cancers using the large volume of data in the Japan Children's Cancer Registry (JCCR). We focused on childhood leukemia, which comprises about $41 \%$ of all childhood cancers and has the largest number of cases.

\section{Methods}

\subsection{Introduction of Japan Children's Cancer Registry}

Tanimura et al. outlined the JCCR in a previous publication [13]. The JCCR was established in 1969 in order to explore etiological factors for the occurrence of childhood cancers. This registry is nation-wide and hospital-based. 
Questionnaire sheets were sent to attending doctors who treat children with cancers. They were asked to make medical records that included a questionnaire that was filled in at the time of interview with the parents. After pathological confirmation of the details of cancer diagnosis, the questionnaire was completed with information from medical records and sent back to the registration center. The contributing doctors were mostly pediatricians and pediatric surgeons.

\subsection{Methods of Data Collection}

The questionnaire sheet has been revised twice. The original questionnaire did not include information on parental smoking habits, and the first revision, which was made in 1978, included maternal smoking histories only. The second revision was made in 1985 and included information on the smoking habits of both parents. Because the majority of contributing doctors were pediatricians and pediatric surgeons, more than $40 \%$ of registered cancers were leukemia; therefore, we focused on acute leukemia for our analysis. Information on the smoking statuses of fathers was available for 4,802 acute leukemia cases diagnosed between 1985 and 2006. Information on the smoking status of mothers was available for 5,536 acute leukemia cases diagnosed between 1978 and 2006.

Because information on smoking included the ages at which parents started and stopped smoking, we examined smoking status in relation to pregnancy. We found that the majority of fathers who started to smoke before conception continued to smoke thereafter, whereas most smoking mothers stopped smoking temporarily during pregnancy. Therefore, we decided to classify parents as non-smokers or smokers if they smoked more than 20 cigarettes/day (c/d) from the preconception period.

\subsection{Methods of Calculation of Odds Ratios}

We compared the smoking rates of parents whose children were diagnosed with leukemia with a control group of parents whose children were diagnosed with benign tumors or cancer-related diseases, which included Langerhans cell histiocytosis, benign or mature teratoma, adenomas of various organs, and fibroma. We did not differentiate acute lymphoblastic leukemia and acute myeloblastic leukemia because of the peculiar classification system of leukemia that was employed in Japan, especially in the eastern part of the country, until the 1970s [14].

Odds ratios (OR) and 95\% confidence intervals were calculated using SPSS ver. 22 software.

\subsection{Ethical Consideration}

This registration and the usage of data extracted from the medical records for research work were approved by the Ethical Committee of Kyorin University (No. 348).

\section{Results}

\subsection{Smoking Rates of Fathers}

The smoking rate $(62.2 \%)$ of fathers who smoked more than $20 \mathrm{c} / \mathrm{d}$ and whose children were diagnosed with acute leukemia was higher than that of the control (55.2\%) (Table). Moreover, dose-response was observed between the amount of cigarettes consumed and occurrence of leukemia: OR 1.284 for $1-9 \mathrm{c} / \mathrm{d}$ before conception $(\mathrm{p}=0.127), 1.265$ for $10-19 \mathrm{c} / \mathrm{d}(\mathrm{p}=0.029)$, and 1.345 for more than $20 \mathrm{c} / \mathrm{d}$ $(p=0.000)$. A logistic regression analysis controlling for sex, birth weight, paternal age at birth, and maternal smoking showed that the smoking rate of fathers whose children had acute leukemia was still significantly higher (OR 1.012, $\mathrm{p}=0.004)$.

\subsection{Smoking Rates of Mothers}

Regarding maternal smoking more than $20 \mathrm{c} / \mathrm{d}$, the difference of the smoking rate between mothers whose children had acute leukemia and the control was not significant (OR 1.161, $\mathrm{p}=0.447$ ).

Table 1. Odds ratios of parental smoking rates (more than 20 cigarettes/day).

\begin{tabular}{|c|c|c|c|c|c|c|c|c|}
\hline \multirow{2}{*}{$\begin{array}{l}\text { Childhood } \\
\text { Cancers }\end{array}$} & \multicolumn{4}{|l|}{ Father } & \multicolumn{4}{|l|}{ Mother } \\
\hline & $\begin{array}{l}\text { Numbers of } \\
\text { Smoking/Non-smoking }\end{array}$ & OR & $95 \%$ CI & $\begin{array}{l}P \\
\text { value }\end{array}$ & $\begin{array}{l}\text { Numbers of } \\
\text { Smoking/Non-smoking }\end{array}$ & OR & $95 \%$ CI & $\begin{array}{l}P \\
\text { value }\end{array}$ \\
\hline Benign tumors* & $456 / 370$ & 1 & & & $38 / 939$ & 1 & & \\
\hline Leukemia & $2,988 / 1,814$ & 1.337 & $1.151-1,551$ & 0.000 & $255 / 5281$ & 1.16 & $0.820-1.645$ & 0.447 \\
\hline
\end{tabular}

OR: Odds ratio; CI: Confidence interval.

*Benign tumors include Langerhans cell histiocytosis, benign or mature teratoma, adenomas of various organs, and fibroma.

\section{Discussion}

\subsection{Consideration Concerning with Recall Bias}

Because this study was based on the retrospective memory of parents of children diagnosed with cancer, recall bias is inevitable. The smoking rates of mothers were consistent with that reported in the Japanese general population [15]. The birth weights of children whose mothers smoked during pregnancy were always smaller than those of children whose mothers did not smoke (Figure). The birth weight of children whose mothers smoked more was smaller, indicating a dose-response relationship. Relationships between paternal smoking, lower birth weight, and shorter gestational period were not observed. Based on these findings, the smoking status of parents was considered valid. 


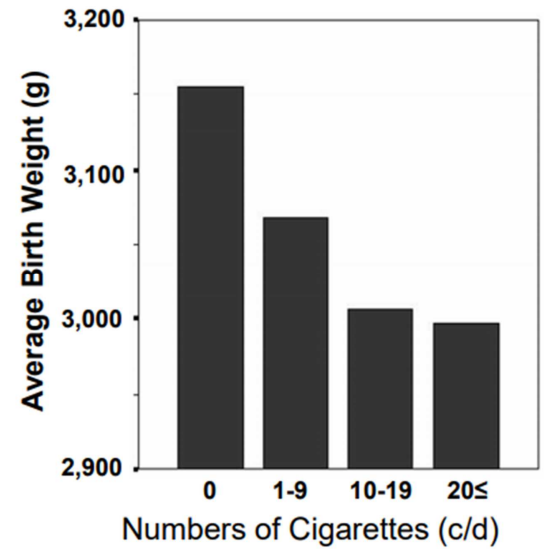

Figure 1. Birth weight of babies born to mothers who smoked during pregnancy.

\subsection{General Discussion}

Our result clearly shows that the fathers' smoking was related to acute leukemia in children, whereas the mothers' smoking seems not to be related. Even after excluding several possible confounding factors, this relationship was confirmed. Previous studies reported that smoking habits among fathers, rather than mothers $[6,16,17-21]$, are associated with the development of cancers, including leukemia, in their children. Our results are consistent with these findings.

Meta-analyses and reviews were published on the effects of parental smoking on the occurrence of childhood cancers [22-24]; however, the conclusions of these meta-analyses regarding the effects of parental smoking remain unclear. In addition to possible conflicts of interests in some of these meta-analyses [25, 26], the number of subjects in the original studies were relatively small, and various degrees of recall bias concerning smoking habits were inevitable. A cohort study is more suitable for avoiding recall bias, but it is difficult to conduct because of the rarity of childhood cancers. Two reviews included only 33 and 327 cases of childhood cancers that developed in a cohort of approximately 16,000 to 500,000 children $[23,24]$. A large number of confounding factors also influence the occurrence of childhood cancers. In addition, childhood diseases, such as acute lymphocytic leukemia, are often heterogeneous. Although B-precursor ALL with t (12; 21 ) is likely to be associated with the father's smoking before and after delivery, such an association was not observed among ALL with hyperdiploid chromosomes in previous studies [21]. Additionally, susceptibility to genotoxic substances differs among individuals [20]. Therefore, more studies need to be accumulated.

Since Grufferman's report [6] and hypothesis [27] regarding the importance of paternal smoking on the occurrence of childhood cancers, many studies have shown that paternal rather than maternal smoking is more important for occurrence of childhood cancers. The duration of exposure to genotoxic substances in the fetus is only 10 months at maximum, which may not be sufficient for the fetus to develop adverse genetic changes. Moreover, because it may take several decades for cancer to develop after exposure to carcinogenic agents, such as alkylating drugs, cancers may not become apparent during childhood [28, 29]. Another possibility is that mothers may underreport their smoking habits because of feelings of guilt [30]. This may also explain the negative effects of maternal smoking on some childhood cancers.

On the other hand, evidence that paternal smoking has serious adverse effects on the functional and morphological quality of sperm is increasing [31], with even secondhand smoking causing germline mutations [32, 33]. Moreover, tobacco smoke contains fine particulate matter [34, 35] that can disrupt blood-testis barrier to accelerate the action of genotoxic chemicals in tobacco smoke in addition to its own influence on sperm qualities [36, 37]. Thus, the effects of paternal smoking on the occurrence of childhood cancers may be related to the effects of tobacco smoke on sperm.

Because of the retrospective nature of the present study, possible confounding factors known to be related to the occurrence of childhood acute leukemia could not be examined. However, because the control subjects in this study were chosen from children registered to the same registry, these confounding factors may be evenly distributed between both groups.

\section{Conclusion}

Our study confirmed that Father's smoking rather than mother's smoking increases the risk of childhood ALL. Fathers should stop smoking to prevent secondhand smoking of their partners and when they want to have children should stop smoking as soon as possible.

\section{Conflict of Interest Statement}

All the authors do not have any possible conflicts of interest.

\section{Acknowledgements}

We thank the physicians engaged in the program of the Japan Children's Cancer Registry and Ms. Harumi Hayashi for entering data into the database file.

\section{References}

[1] Talhout R, Schulz T, Florek E, van Benthem J, Wester P, Opperhuizen A. Hazardous compounds in tobacco smoke. Int J Environ Res Public Health 2011; 8: 613-628.

[2] Wild CP, Kleinjans J. Children and increased susceptibility to environmental carcinogens: evidence or empathy? Cancer Epidemiol, Biomarkers Prev. 2003; 12: 1389-1394.

[3] Pichini S, Basagaña XB, Pacifici R et al. Cord serum cotinine as a biomarker of fetal exposure to cigarette smoke at the end of pregnancy. Environ Health Perspect. 2000; 108: 1079-1083.

[4] Thomas JL, Guo H, Carmella SG et al. Metabolites of a tobacco-specific lung carcinogen in children exposed to secondhand or thirdhand tobacco smoke in their homes. Cancer Epidemiol, Biomarkers Prev 2011; 20: 1213-1221. 
[5] de Assis KR, Ladeira MS, Bueno RC, Dos Santos BF, Dalben I, Salvadori DM. Genotoxicity of cigarette smoking in maternal and newborn lymphocytes. Mutat Res 2009; 679: $72-78$.

[6] Grufferman S, Wang HH, DeLong ER, Kimm SY, Delzell ES, Falletta JM. Environmental factors in the etiology of rhabdomyosarcoma in childhood. J Nat Cancer Inst 1982; 68: 107-113.

[7] Stjernfeldt M, Berglund K, Lindsten J, Ludvigsson J. Maternal smoking during pregnancy and risk of childhood cancer. Lancet 1986; 1: 1350-1352.

[8] John EM, Savitz DA, Sandler DP. Prenatal exposure to parents' smoking and childhood cancer. Am J Epidemiol 1991; 133: 123-132.

[9] Schwartzbaum JA. Influence of the mother's prenatal drug consumption on risk of neuroblastoma in the child. Am J Epidemiol 1992; 135: 1358-1367.

[10] Pershagen G, Ericson A, Otterblad-Olausson P. Maternal smoking in pregnancy: does it increase the risk of childhood cancer? Int J Epidemiol 1992; 21: 1-5.

[11] Sorahan T, Lancashire R, Prior P, Peck I, Stewart A. Childhood cancer and parental use of alcohol and tobacco. Ann Epidemiol 1995; 5: 354-359.

[12] Ji BT, Shu XO, Linet MS et al. Paternal cigarette smoking and the risk of childhood cancer among offspring of nonsmoking mothers. J Nat Cancer Inst 1997; 89: 238-244.

[13] Tanimura M, Matsui $I$, Abe $J$ et al. Increased risk of hepatoblastoma among immature children with a lower birth weight. Cancer Res 1998; 58: 3032-3035.

[14] Bessho F: Acute non-lymphocytic leukemia is not a major type of childhood eukemia in Japan. Eur J Cancer Clin Oncol 1989; 25: 729-732.

[15] Ministry of Health, Labour and Welfare: National Health and Nutrition Survey in Japan 2013 home page. http://www.mhlw.go.jp/bunya/kenkou/eiyou/h25-houkoku.ht ml. July 7, 2015 Accessed July 7, 2015.

[16] Sorahan T, Lancashire RJ, Hulten MA, Peck I, Stewart AM. Childhood cancer and parental use of tobacco: deaths from 1953 to 1955 . Br J Cancer 1997; 75: 134-138.

[17] Chang JS, Selvin S, Metayer C, Crouse V, Golembesky A, Buffler PA. Parental smoking and the risk of childhood leukemia. Am J Epidemiol 2006; 163: 1091-1100.

[18] Rudant J, Menegaux F, Leverger G et al. Childhood hematopoietic malignancies and parental use of tobacco and alcohol: the ESCALE study (SFCE). Cancer Causes Control 2008; 19: 1277-1290.

[19] Plichart M, Menegaux F, Lacour B et al. Parental smoking, maternal alcohol, coffee and tea consumption during pregnancy and childhood malignant central nervous system tumours: the ESCALE study (SFCE). Eur J Cancer Prev 2008; 17: 376-383.

[20] Lee KM, Ward MH, Han S et al. Paternal smoking, genetic polymorphisms in CYP1A1 and childhood leukemia risk. Leuk Res 2009; 33: 250-258.

[21] Metayer C, Zhang L, Wiemels JL et al. Tobacco smoke exposure and the risk of childhood acute lymphoblastic and myeloid leukemias by cytogenetic subtype. Cancer Epidemiol Biomarkers Prev 2013; 22: 1600-1611.

[22] Pershagen G. Childhood cancer and malignancies other than lung cancer related to passive smoking. Mutat Res 1989; 222: 129-135.

[23] Tredaniel J, Boffetta P, Little J, Saracci R, Hirsch A. Exposure to passive smoking during pregnancy and childhood, and cancer risk: the epidemiological evidence. Paediatr Perinat Epidemiol 1994; 8: 233-255.

[24] Boffetta P, Tredaniel J, Greco A. Risk of childhood cancer and adult lung cancer after childhood exposure to passive smoke: A meta-analysis. Environ Health Perspect 2000; 108: $73-82$.

[25] Sasco AJ, Vainio H. From in utero and childhood exposure to parental smoking to childhood cancer: a possible link and the need for action. Hum Exp Toxicol 1999; 18: 192-201.

[26] Barnes DE, Bero LA. Why review articles on the health effects of passive smoking reach different conclusions. JAMA 1998; 279: $1566-1570$.

[27] Grufferman S, Delzell ES, Maile MC, Michalopoulos G. Parents' cigarette smoking and childhood cancer. Med Hypotheses 1983; 12: 17-20.

[28] Everson RB. Individuals transplacentally exposed to maternal smoking may be at increased cancer risk in adult life. Lancet 1980; 2: 123-127.

[29] Maurizi-Enrici R. Anselmo AP, Osti MF et al. Analysis of the risk of solid tumor following Hodgkin's disease. Haematologica 1997; 82: 57-63.

[30] Pang D, McNally R, Birch JM. Parental smoking and childhood cancer: results from the United Kingdom Childhood Cancer Study. Br J Cancer 2003; 88: 373-381.

[31] Elshal MF, El-Sayed IH, Elsaied MA, El-Masry SA, Kumosani TA. Sperm head defects and disturbances in spermatozoal chromatin and DNA integrities in idiopathic infertile subjects: association with cigarette smoking. Clin Biochem 2009; 42: 589-594.

[32] Yauk CL, Berndt ML, Williams A, Rowan-Carroll A, Douglas GR, Stämpfli MR. Mainstream tobacco smoke causes paternal germ-line DNA mutation. Cancer Res 2007; 67: 5103-5106.

[33] Pereira CS, Juchniuk de Vozzi MS, Dos Santos SA et al. Smoking-induced chromosomal segregation anomalies identified by FISH analysis of sperm. Mol Cytogenet 2014; 7 : 58 .

[34] Gerber A, Hofen-Hohloch AV, Schulze J, Groneberg DA. Tobacco smoke particles and indoor air quality (ToPIQ-II) - a modified study protocol and first results. J Occup Med and Toxol 10: 5 DOI 10.1186/s12995-015-0047-8.

[35] Braun M, Fromm EL, Gerber A, Klingelhöfer D, Müller R, Groneberg DA. Particulate matter emissions of four types of one cigarette brand with and without additives: a laser spectrometric particulate matter analysis of secondhand smoke. BMJ Open 2019; 9: e024400. doi: 10.1136/bmjopen2018-024400.

[36] Lao XQ, Zhang Z, Lau AKH et al. Exposure to ambient fine particulate matter and semen quality in Taiwan. Occup Environ Med 2018; 75: 148-154. 
[37] Liu J, Ren L, Wei J et al. Fine particle matter disrupts the blood-testis barrier by activating TGF-beta3/p38 MAPK pathway and decreasing testosterone secretion in rat. Environ Toxicol 2 018; 33: 711-719. 